\title{
Doctors call for lawyers to get out of hospitals
}

\author{
Dr Aaron Motsoaledi, MP, Minister of Health, South Africa
}

Keynote Address at the Medico-Legal Summit, St George's Hotel, Pretoria

9- 10 March 2015

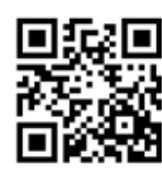

Let me welcome you heartily to this very important Summit, which needless to say, has been long overdue. There is definitely a lot of anxiety within both the medical and the legal professions on the expected outcome of this Summit, albeit for totally different and opposing reasons.

Please get used to the idea that from now, henceforth, whenever we meet in this fashion, I am going to keep on reminding you that South Africa has a plan - the National Development Plan (NDP) or Vision 2030.

This is because every summit, conference, plan, strategy, resolution, declaration, and debate in health, will have to align itself with the NDP.

For those who do not or did not read the NDP, let me remind you what it says about health:

'We envisage that in 2030, South Africa has a life expectancy rate of at least 70 years for men and women. The generation of under$20 \mathrm{~s}$ is largely free of HIV. The quadruple burden of disease has been radically reduced compared to the two previous decades, with an infant mortality rate of less than 20 deaths per thousand live births and an under-five mortality rate of less than 30 per thousand. There has been a significant shift in equity, efficiency, effectiveness and quality of health care provision.

'Universal coverage is available. The risks posed by the social determination of disease and adverse ecological factors have been reduced significantly.

It goes on to say that: 'This vision will only be achievable if the major problems that currently exist in the three perspectives are addressed effectively'.

Ladies and gentlemen, we are determined, as a government, to achieve Vision 2030 as outlined. We have to, we do not have any option. If we are to achieve the goal of a long and healthy life for all South Africans, we have to!

There are three main events, or should I say issues, that will be major determining factors of whether we indeed can achieve the goals of the NDP.

In fact, these three issues, which are all going to happen this year 2015 , will make or break the health system in this country. The three of them are going to change the health system as we know it today. Unfortunately, the change they may bring may be either positive or negative, depending on our attitude as South Africans.

These three are:

- the outcomes of the White Paper on the National Health Insurance (NHI);

- the outcome of former Chief Justice Ngcobo's public market inquiry into the cost of private health as set out by the Competition Commission; and

- the outcome of this very Summit on medico-legal litigation tomorrow.
I repeat - these three will make or break the health system as we have come to understand it in South Africa.

Let me leave the Competition Commission's Market Inquiry and NHI White Paper because their time is coming - soon for that matter.

Let me focus on the third - which brought us here today, and that is - medico-legal litigation.

Has medico-legal litigation reached a crisis point in South Africa?

The answer is definitely a big Yes. It is a crisis of large proportions.

It is the same crisis that engulfed Australia a decade-and-a-half ago when their general insurance collapsed, followed immediately by the provisional liquidation of Australia's largest medical defence organisation - the United Medical Protection.

It is the same crisis that occurred in the United States (US) in the early 1970s which was described as a crisis of insurance availability as many insurers exited. The second in the mid 1980s was a crisis of affordability with price hikes that meant that doctors found they could not afford to pay for cover.

Both of these crises prompted a concern about access to certain services - obstetrics and emergency care in particular.

The most recent crisis in the US was precipitated when certain companies exited the market en masse, which led to a crisis of affordability as well as availability.

Unfortunately, we in South Africa seem to be heading very fast in that same direction.

Yes programme director, we are certainly headed in the direction which hit the United Kingdom (UK) in the not so distant past when a big debate in the House of Commons dubbed 'The Big Storm' ensued.

What is the nature of this crisis in South Africa today? Are we faced with our own 'Big Storm'?

The nature of the crisis is that our country is experiencing a very sharp increase - actually an explosion - in medical malpractice litigation which is not in keeping with generally known trends of negligence or malpractice.

The cost of medical malpractice claims have sky-rocketed and the number of claims increased substantially.

When it first started being noticed, those who have made a habit of rubbishing the Public Health system at every available opportunity jumped in without an iota of research and concluded that the reason is the rising negligence or what they call the 'don't care attitude' in public healthcare in our country - and started lambasting the State about it.

Let me make it very clear - the crisis we are faced with is not a crisis of public healthcare in our country - it is a crisis faced by everybody in the healthcare profession - public and private - it does not matter where you are. As long as you are in health, the crisis affects you.

Ominously, the crisis does not affect all medical specialities in the same manner. From the trends, we notice that certain specialities are being targeted more than others. 
There are four medical specialities that are continuously, persistently and mercilessly being targeted for litigation.

These are:

- Obstetrics and Gynaecology

- Neurosurgery

- Neonatology

- Orthopaedics.

Whether you are in public or private as long as you practise in these specialities, you are a major target.

No rocket science is needed to figure out why these are the specialities that are specifically targeted.

I am painfully aware that at this present moment in our country, there are many divergent views as to the cause of this explosion in medico-legal litigation.

When Australians were faced with a similar fate, as I mentioned earlier, there was considerable disagreement at the time about the factors that led to the crisis: some commentators blamed insurers poor business practice and the cyclical nature of the insurance industry. The government and the insurance companies held the justice system responsible, arguing that it was too lenient and that damage awards were too generous. Some claimed that doctors have become too careless etc. etc.

Whichever view you hold, whoever you wish to blame, the fact that needs to be confronted is that this is a crisis that is destructive to the health system of a country - not just the healthcare system, but the whole system of health.

When this crisis reached a boiling point in Ireland in the 1990s, the commercial insurance market had reached a point whereby it was no longer willing to provide insurance cover for obstetricians and gynaecologists or to hospitals with obstetric units due to the escalation in the size of court awards and costs in cases of birthrelated cerebral dysfunction.

The latter fact, i.e. birth-related cerebral dysfunction, is the one we are faced with in South Africa today - a quarter of a century later.

In our country, the cost of indemnity insurance for private specialists in neurosurgery increased by a whopping $573 \%$ within a period of eight years between 2005 and 2013, and is still going up and up.

I believe the Medical Protection Society will give the recent figures today.

The cost of indemnity insurance for private specialist in obstetrics increased by $382 \%$ within a similar period, and is still growing. Again, the Medical Protection Society will hopefully give the most recent figures.

All these issues have devastating consequences to a health system of a country.

We know that some doctors who were interviewed by the Medical Protection Society made chilling statements like: 'I now consider every patient in front of me as a potential enemy'.'I now consider that every consultation may end in a claim'. 'I now refer more patients to other doctors, I now choose which conditions to treat and which to reject'.' I am thinking of a career change'.

This last statement holds a potential disaster to the welfare of all women in our country because from where I am, we are getting reports that doctors are now reluctant to specialise in obstetrics and gynaecology.

Those who are too old to change are resorting to practicing gynaecology and refuse to see the woman once she falls pregnant.
Just close your eyes tightly and imagine a country with many many super-rich lawyers but no obstetricians at all! That will be back to the Stone Age. It is tantamount to declaring a death sentence to women and children.

It is this prospect that prompted the British Secretary of State for Health, the honourable Frank Dobson, during the debate dubbed 'The Big Storm' in the UK on this very same issue when he said:

I had a slogan: keep doctors out of courts and lawyers out of hospitals. I once made the unseemly suggestion that the only place for a lawyer in a hospital was on the operating table. Apart from visiting, that still broadly applies. We must change the law and take seriously what happens outside the hospital if we are to improve what happens inside it. I strongly support the report's recommendation 119 to replace the current inadequate, slow, unsatisfactory, grotesquely expensive and lawyers' pocket and handbag-lining system of dealing with clinical negligence.

'The system's main fault is that it is bad for patients' safety. My right hon. friend the Secretary of State said that patients and their safety must come first in the NHS. They must also come first in our legal system.

'I welcome the chief medical officer's work in bringing people together to try to find a compensation system that is fair to those who have suffered but does not damage others who will be treated in future. When the government present their proposals and we consider them, we should revert to the point that patients and their safety must be the top priority.

Programme director, I believe that this speech by the honourable Dobson, Minister in the House of Commons, perhaps summarises better the gist of what brought us here today!

Patient safety should be our major concern and the central core of the outcomes of this Summit.

I am painfully aware that this statement may lead the cynics and sceptics to conclude that the explosion of medical litigation is a direct result of patients' safety being severely compromised. A few weeks ago, when an unauthorised report about the workshop of the stakeholders I convened to prepare for this Summit was wrongfully released, many lawyers who commented took this view - yes if they are not negligent, there will be no litigation. If patients are all safe, there will be no problem.

Let us be brutally honest, many of the highly litigating lawyers care less about the concept of patient safety. They are driven by this pocket-lining phenomenon described by the British Minister. They are simply in hospitals because the platform from which they have been lining their pockets - and not that of the wronged patients - has now changed.

Yes, the RAF (Road Accident Fund) has changed. It has been bankrupted by this pocket-lining behaviour.

That behaviour had nothing to do with safeguarding patients who were injured on our roads. You do not safeguard their interest by bankrupting the scheme that has been established for their benefit.

In the same vein, you cannot guarantee patient safety in South Africa by litigating caregivers out of practice or by depriving the healthcare system of its much needed resources by devising schemes that suck out money from the healthcare system, so fast that the system cannot even replenish itself.

Hence programme director, it is us in health who must safeguard the safety of patients. That is why the British, in dealing with this 
problem, established a British Quality Care Commission alongside the British Litigation Authority.

This means that the solutions we must adopt to resolve this problem will be:

- first and foremost medical

- then administrative

- then legal.

Our medical solutions will be centred on patient safety and patient welfare.

I can announce to you today that we shall soon advertise the position of the country's first Health Ombudsperson who would enforce patient safety and welfare.

I am encouraging the Office of Health Standards Compliance to work around the clock to make sure that inspectors are ready and their presence is felt in hospitals.

The Health Ombud will examine breaches of standards and norms, for both patient redress and system improvement. It will complement the existing investigations of professional negligence.

Let me also take this opportunity to inform you that tomorrow, I wish to make an announcement about the HPCSA (Health Professions Council of South Africa) on this very issue.

Other initiatives to improve quality of care will be:

- improvement in clinical governance

- accelerate the training in ESMOE

- rehabilitation of health infrastructure

- a non-negotiable approach on procurement and maintenance of equipment and medical devices.

We shall appeal to the chief procurement officer in the Treasury to expedite this issue of procuring all equipment and devices for our health facilities.

I will not venture into the legal solutions. I will leave them to the Summit - safe to mention two things:

- We are not going to escape the changes RAF is making to safeguard the Fund, but without jeopardising the interest of accident victims. That is why RAF is here to share with us how it is being done.

- We are very much aware that the same syndicates which bankrupted RAF are very much busy in health.

People are working in syndicates - to achieve their aim which is one - to line their pockets in the name of patients who might have been victims in one way or the other.
We are aware that these syndicates consist of lawyers and some within the health profession itself to make as much money from the State and other doctors as possible.

We are aware that members of these syndicates in the various State Attorney Offices are mismanaging cases deliberately, so that the State must lose at all times.

We are aware that some hospital CEOs are not doing anything to safeguard the welfare of patients but instead deliberately jeopardise the welfare of patients and immediately report to the legal members of these syndicates to start litigation.

We regard these people as having declared war on the health system of the country and hence will deserve no mercy when they are finally caught.

In conclusion programme director, let me make it very clear, that the final loser in this state of affairs, is not necessarily the government and the health profession as many seem to be thinking. Of course the government is the loser if things are not going well in any aspect of life within a country. The healthcare profession is the loser if things go wrong, but the ultimate loser is the public.

Why?

- Doctors are now forced to practice medicine in the way they have been taught, but are forced to apply the principles of law within clinical practice, and these are not always compatible.

- Because doctors are forced to order investigations or to perform tests for the benefit of lawyers and not patients, many patients are subjected to unnecessary physical and emotional pain, but also they have to pay for these unnecessary tests.

- Healthcare inflation has sky-rocketed and people are forced to pay more for their medical aid subscription because doctors, especially obstetricians, neurosurgeons, neonatologists and orthopaedic surgeons have to charge more, because they are forced to pay huge amounts of money in purchasing indemnity even before they start practising.

- The healthcare budget will have to be increased tremendously just to cater for this escalating litigation. When budgets are forced to increase, taxes also increase, affecting the public. I do not have to remind you that the Minister of Finance has increased the fuel levy in order to cover the shortfall in RAF, which was caused by this excessive litigation and fraud as reported in last week's papers.

Ladies and gentlemen, I declare this very challenging Summit officially open! I thank you.

S Afr J BL 2015;8(1):4-6. DOI:10.7196/SAJBL.409 